JAMA Internal Medicine | Original Investigation

\title{
Diagnostic Accuracy of Symptoms, Physical Signs, and Laboratory Tests for Giant Cell Arteritis A Systematic Review and Meta-analysis
}

Kornelis S. M. van der Geest, MD, PhD; Maria Sandovici, MD, PhD; Elisabeth Brouwer, MD, PhD; Sarah L. Mackie, MD, PhD

IMPORTANCE Current clinical guidelines recommend selecting diagnostic tests for giant cell arteritis (GCA) based on pretest probability that the disease is present, but how pretest probability should be estimated remains unclear.

OBJECTIVE To evaluate the diagnostic accuracy of symptoms, physical signs, and laboratory tests for suspected GCA.

DATA SOURCES PubMed, EMBASE, and the Cochrane Database of Systematic Reviews were searched from November 1940 through April 5, 2020.

STUDY SELECTION Trials and observational studies describing patients with suspected GCA, using an appropriate reference standard for GCA (temporal artery biopsy, imaging test, or clinical diagnosis), and with available data for at least 1 symptom, physical sign, or laboratory test.

DATA EXTRACTION AND SYNTHESIS Screening, full text review, quality assessment, and data extraction by 2 investigators. Diagnostic test meta-analysis used a bivariate model.

MAIN OUTCOME(S) AND MEASURES Diagnostic accuracy parameters, including positive and negative likelihood ratios (LRs).

RESULTS In 68 unique studies ( 14037 unique patients with suspected GCA; of 7798 patients with sex reported, 5193 were women [66.6\%]), findings associated with a diagnosis of GCA included limb claudication (positive LR, 6.01; $95 \% \mathrm{Cl}, 1.38-26.16$ ), jaw claudication (positive $\mathrm{LR}, 4.90 ; 95 \% \mathrm{Cl}, 3.74-6.41$ ), temporal artery thickening (positive $\mathrm{LR}, 4.70 ; 95 \% \mathrm{Cl}$, 2.65-8.33), temporal artery loss of pulse (positive $L R, 3.25 ; 95 \% \mathrm{Cl}, 2.49-4.23$ ), platelet count of greater than $400 \times 10^{3} / \mu \mathrm{L}$ (positive LR, 3.75; 95\% Cl, 2.12-6.64), temporal tenderness (positive LR, 3.14; 95\% Cl, 1.14-8.65), and erythrocyte sedimentation rate greater than 100 $\mathrm{mm} / \mathrm{h}$ (positive $\mathrm{LR}, 3.11 ; 95 \% \mathrm{Cl}, 1.43-6.78$ ). Findings that were associated with absence of GCA included the absence of erythrocyte sedimentation rate of greater than $40 \mathrm{~mm} / \mathrm{h}$ (negative LR, $0.18 ; 95 \% \mathrm{Cl}, 0.08-0.44$ ), absence of C-reactive protein level of $2.5 \mathrm{mg} / \mathrm{dL}$ or more (negative LR, $0.38 ; 95 \% \mathrm{Cl}, 0.25-0.59$ ), and absence of age over 70 years (negative LR, $0.48 ; 95 \% \mathrm{Cl}, 0.27-0.86)$.

CONCLUSIONS AND RELEVANCE This study identifies the clinical and laboratory features that are most informative for a diagnosis of GCA, although no single feature was strong enough to confirm or refute the diagnosis if taken alone. Combinations of these symptoms might help direct further investigation, such as vascular imaging, temporal artery biopsy, or seeking evaluation for alternative diagnoses.

JAMA Intern Med. doi:10.1001/jamainternmed.2020.3050

Published online August 17, 2020.
Invited Commentary

Supplemental content
Author Affiliations: Department of Rheumatology and Clinical Immunology, University of Groningen, University Medical Center Groningen, Groningen, the Netherlands (van der Geest, Sandovici, Brouwer); Leeds Institute of Rheumatic and Musculoskeletal Medicine, NIHR (National Institute for Health Research) Leeds Biomedical Research Centre, Leeds Teaching Hospitals NHS (National Health Service) Trust, University of Leeds, Leeds, United Kingdom (Mackie).

Corresponding Author: Kornelis S. M. van der Geest, MD, PhD, Department of Rheumatology and Clinical Immunology, University of Groningen, University Medical Center Groningen, Hanzeplein 1, Groningen 9700RB, the Netherlands (k.s.m.van.der.geest@umcg.nl). 
G iant cell arteritis (GCA) is a "do-not-miss" diagnosis. Prompt diagnosis can avert visual loss. ${ }^{1}$ Diagnosis can be delayed in those without the classic cranial features, such as headache. ${ }^{2}$ Treatment for GCA consists of highdose glucocorticoids tapered during the course of 1 year or more, but this treatment may cause substantial toxic effects, so diagnostic uncertainty must be minimized. ${ }^{3}$

Making a diagnosis of GCA can be challenging. The American College of Rheumatology 1990 criteria for the classification of GCA in research studies should not be used for clinical diagnosis. ${ }^{4,5}$ Instead, temporal artery biopsy (TAB; highly specific but with imperfect sensitivity), ${ }^{6}$ vascular imaging (ultrasonography, computed tomography, magnetic resonance imaging, or positron emission tomography), ${ }^{7}$ or a combination of these tests are recommended. ${ }^{3,7}$ These further investigations should be selected based on pretest probability. ${ }^{3,7}$ The difficulty in practice is how to quantify pretest probability given only symptoms, signs, and, if available, laboratory features. Regression, machine learning models, or clinical scoring systems have been suggested, but these rely on complete information and still require further validation. ${ }^{8,9}$ Pretest probability might additionally be estimated by using likelihood ratios (LRs) of clinical features to allow sequential bayesian probability revision. ${ }^{10}$ A previous meta-analysis ${ }^{11}$ reported pooled estimates of the LRs of clinical and laboratory features for a positive TAB finding. However, this previous meta-analysis included studies comparing TAB-positive vs TAB-negative GCA, which is not appropriate for estimating diagnostic accuracy. The previous meta-analysis also included diagnostic casecontrol studies, which often overestimate diagnostic accuracy. ${ }^{12,13}$ Since the earlier meta-analysis, ${ }^{11}$ many more relevant studies have been published. ${ }^{14-17}$

We conducted a systematic review and meta-analysis of the diagnostic accuracy of symptoms, physical signs, and laboratory tests for GCA. We provide summary estimates of the sensitivity, specificity, and LRs of these features. We included studies using appropriate reference standards for GCA, including TAB and clinical diagnosis. We excluded case-control studies and studies in which all patients were classified as having GCA.

\section{Methods}

This study is reported in accordance with the 2009 Preferred Reporting Items for Systematic Reviews and Meta-analyses (PRISMA) reporting guideline. ${ }^{18}$ A predefined study protocol was established but not registered. No ethical approval or informed consent was required for the current systematic review and meta-analysis.

\section{Data Sources and Search Strategy}

We searched PubMed, EMBASE, and the Cochrane Database of Systematic Reviews from December 1940 to April 5, 2020. The search strategy included terms such as giant cell arteritis, temporal arteritis, medical history taking, physical examination, diagnostic imaging, and artery biopsy. The full search strategy was developed together with an experienced medical science librarian (eTable 1 in the Supplement). We included

\section{Key Points}

Question In patients with suspected giant cell arteritis, which clinical and laboratory findings can help to identify the disease?

Findings This systematic review and meta-analysis of 68 unique diagnostic cohort studies (14 037 unique patients) identified combinations of symptoms, physical signs, and laboratory tests that were informative with regard to the presence or absence of giant cell arteritis, but no single feature taken alone. Headache and scalp tenderness were poorly informative in this population.

Meaning These findings suggest that in patients with suspected giant cell arteritis, no single clinical or laboratory feature is sufficient to rule in or rule out the disease; therefore, additional investigations (vascular imaging and/or temporal artery biopsy) are required.

English language records. Case reports and conference abstracts were excluded. The reference lists of included studies were screened for additional records.

\section{Study Selection and Eligibility Criteria}

We included clinical trials and prospective or retrospective observational studies that met the following criteria: (1) participants were consecutive patients suspected of having GCA; (2) a TAB, imaging test, or clinical diagnosis was used as the reference standard for GCA; (3) a table of the true-positive, false-positive, true-negative, and false-negative counts was either directly available or could be calculated for at least 1 index test (symptom, physical sign, or laboratory test); and (4) at least 5 patients had GCA and at least 5 did not have GCA. The reference standard clinical diagnosis could be based on defined criteria or judgment of 1 or more physicians. We considered healed temporal arteritis (ie, intimal hyperplasia and/or internal elastic lamina disruption in the absence of an arterial inflammatory infiltrate) as a negative TAB result, because it might indicate atherosclerosis rather than GCA. ${ }^{6}$ We excluded studies in which all patients were diagnosed with GCA and/or the closely related disease polymyalgia rheumatica. ${ }^{19}$ We excluded case-control studies. Titles and abstracts were screened by 2 independent reviewers (K.S.M.vdG. and M.S.). Full texts were independently assessed in Covidence by 2 reviewers (K.S.M.vdG. and M.S. or S.L.M.). Disagreement between reviewers was resolved by consensus or, if consensus could not be obtained, by consulting a third reviewer (E.B.) who made the final decision.

\section{Data Collection}

Study characteristics and data from $2 \times 2$ tables were extracted by 1 reviewer (K.S.M.vdG.) and checked by a second reviewer (E.B. or S.L.M.). A standardized data sheet was used to collect information on study characteristics (eAppendix in the Supplement). We extracted any clinical or laboratory finding reported, as well as data on age and sex. Composite findings (eg, symptom A plus symptom B) were not recorded. Authors of studies were not contacted. If potential data overlap existed among studies from the same hospital, data were obtained from the largest study. When multiple reference standards were available in 1 study, the clinical diagnosis was used 
as the reference standard for the main study analysis. A C-reactive protein (CRP) level of less than $0.5 \mathrm{mg} / \mathrm{dL}$ (to convert to $\mathrm{mg} / \mathrm{L}$, multiply by 10 ) was considered the reference value unless other laboratory-specific reference values were reported. Disagreement between reviewers was either resolved by consensus or, if consensus could not be obtained, by consulting a third reviewer (E.B. or S.L.M.), who made the final decision.

\section{Quality Assessment}

The risk of bias was evaluated by 2 reviewers (K.S.M.vdG. and E.B.) with the quality assessment of diagnostic accuracy studies (QUADAS-2) tool (eAppendix in the Supplement). The QUADAS-2 tool focuses on the bias and applicability of study results regarding patient selection, the index test, the reference standard, and study flow and timing. ${ }^{20}$

\section{Synthesis of Results}

Study heterogeneity was evaluated by plotting the estimates of sensitivity and specificity in forest plots and receiver operating characteristics (ROC) space. We used hierarchical logistic regression modeling to determine summary estimates of the sensitivity, specificity, diagnostic odds ratio, and LRs by the bivariate model approach, as well as hierarchical summary ROC (HSROC) plots. ${ }^{21}$ Likelihood ratios of greater than 2.00 or less than 0.50 with $95 \%$ CIs not including 1.00 were considered statistically significant. ${ }^{10,22}$ We performed the following sensitivity analyses: (1) a predefined comparison of LRs in studies using distinct reference standards for GCA; (2) a nonpredefined comparison of LRs in prospective and retrospective studies; and (3) a predefined analysis restricted to pretreatment laboratory tests. Our primary analysis and sensitivity analyses included any index test reported by 4 or more studies. Hierarchical logistic regression modeling analysis and evaluation of funnel plot asymmetry were performed in STATA, version 15.1 (StataCorp LLC) with the metandi, metandiplot, and midas commands. ${ }^{23}$ Forest plots were created in Review Manager, version 5.3 (Cochrane) and StatsDirect, version 3.2.10 (StatsDirect Ltd).

\section{Results}

\section{Study Characteristics}

Of the 1436 reports screened, 68 studies ${ }^{14-17,24-87}$ fulfilled the selection criteria and were used for the systematic review and meta-analysis (eFigure 1 in the Supplement). These studies included 14037 patients, of whom 4277 (30.5\%) were classified as having GCA (Table 1 and eTable 2 in the Supplement). Most reports were retrospective cohort studies $(48[70.6 \%])^{14,15,27,29,31,32,34-41,43-46,48-51,53,54,58,59,62,64-68,70-75, ~}$ 77-81,83-87 and performed at academic centers (56 [82.4\%]). ${ }^{16,17,24-35,37,38,40-57,59-62,66-69,72,73,75-84,86,87}$ TAB was

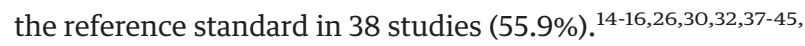
$48,49,52,56,58-60,62,64,65,67,70,72,73,78-81,83-87$ The mean or the median length of the TAB specimen was generally greater than $1 \mathrm{~cm}$. A variable proportion of patients underwent bilateral TAB (eTable 3 in the Supplement). In 30 studies

\begin{tabular}{|c|c|c|}
\hline \multirow[b]{2}{*}{ Characteristic } & \multicolumn{2}{|l|}{ No. $(\%)^{\mathrm{a}}$} \\
\hline & $\begin{array}{l}\text { Studies } \\
(\mathrm{n}=68)\end{array}$ & $\begin{array}{l}\text { Patients } \\
(\mathrm{n}=14037)^{\mathrm{b}}\end{array}$ \\
\hline \multicolumn{3}{|l|}{ Year of publication } \\
\hline Before 1990 & $9(13.2)$ & $797(5.7)$ \\
\hline 1990-1999 & $6(8.8)$ & $1235(8.8)$ \\
\hline $2000-2009$ & $13(19.1)$ & $2119(15.1)$ \\
\hline $2010-2019$ & $40(58.8)$ & $9886(70.4)$ \\
\hline \multicolumn{3}{|l|}{ Study design } \\
\hline Prospective cohort & $20(29.4)$ & $2104(15.0)$ \\
\hline Retrospective cohort & $48(70.6)$ & $11933(85.0)$ \\
\hline \multicolumn{3}{|l|}{ Setting of care } \\
\hline Nonacademic center & $7(10.3)$ & $664(4.7)$ \\
\hline Academic center & $56(82.4)$ & $7777(55.4)$ \\
\hline Nonacademic/academic center & $4(5.9)$ & $3155(22.5)$ \\
\hline Unclear & $1(1.5)$ & $2441(17.4)$ \\
\hline \multicolumn{3}{|l|}{ Identification of patients } \\
\hline Central pathology/surgery registry & $28(41.2)$ & $10337(73.6)$ \\
\hline Central imaging registry & $7(10.3)$ & $412(2.9)$ \\
\hline $\begin{array}{l}\text { Central pathology/surgery } \\
\text { and central imaging registry }\end{array}$ & $2(2.9)$ & $55(0.4)$ \\
\hline Ophthalmology department & $14(20.6)$ & $1452(10.3)$ \\
\hline Rheumatology department & $7(10.3)$ & $709(5.1)$ \\
\hline Multiple hospital departments & $9(13.2)$ & $1006(7.2)$ \\
\hline Unclear & $1(1.5)$ & $66(0.5)$ \\
\hline \multicolumn{3}{|l|}{ Specialty referring patients } \\
\hline Primary care & $1(1.5)$ & $125(0.9)$ \\
\hline Hospital departments & $3(4.4)$ & $481(3.4)$ \\
\hline Primary care and hospital departments & $8(11.8)$ & $2701(19.2)$ \\
\hline Unclear & $56(82.4)$ & $10730(76.4)$ \\
\hline \multicolumn{3}{|l|}{ Laboratory results before treatment } \\
\hline No & $8(11.8)$ & $2779(19.8)$ \\
\hline Yes & $6(8.8)$ & $800(5.7)$ \\
\hline Unclear & $27(39.7)$ & $5824(41.5)$ \\
\hline Not applicable & $27(39.7)$ & $4634(33.0)$ \\
\hline \multicolumn{3}{|l|}{ Type of reference standard } \\
\hline $\mathrm{TAB}$ & $38(55.9)$ & $11207(79.8)$ \\
\hline Clinical diagnosis $^{\mathrm{c}}$ & $30(44.1)$ & $2830(20.2)$ \\
\hline \multicolumn{3}{|l|}{ Focus of diagnostic testing } \\
\hline Cranial arteries & $53(77.9)$ & $12543(89.4)$ \\
\hline Systemic arteries & $1(1.5)$ & $63(0.4)$ \\
\hline Cranial and systemic arteries & $14(20.6)$ & $1431(10.2)$ \\
\hline
\end{tabular}

Abbreviations: GCA, giant cell arteritis; TAB, temporal artery biopsy.

${ }^{\text {a }}$ Percentages have been rounded and may not total 100.

${ }^{\mathrm{b}} \mathrm{A}$ total of 4277 patients were classified as having GCA.

' Seven studies with the clinical diagnosis as the reference standard $^{46,68,71,75-77,82}$ also allowed evaluation of TAB as the reference standard (558 patients). One study with the clinical diagnosis as the reference standard ${ }^{68}$ also allowed evaluation of ultrasonography as the reference standard (23 patients).

(44.1\%), ${ }^{17,24,25,27-29,31,33-36,46,47,50,51,53-55,57,61,63,66,68,69,71,74-77,82}$ clinical diagnosis was the reference standard for GCA; in 8 of these studies, ${ }^{31,46,53,71,75-77,82}$ all patients underwent TAB, and in 9 studies, ${ }^{17,33,47,51,61,63,68,69,74}$ patients had a combination of TAB and imaging (eTable 4 in the Supplement). The clinical 
diagnosis was typically based on clinical and laboratory findings, imaging and/or TAB results, and a good initial response to glucocorticoid treatment (eTable 5 in the Supplement). In 16 of the studies using clinical diagnosis as reference standard, ${ }^{17,29,31,33,34,36,47,51,53,54,57,61,68,69,76,82}$ patients were all followed up to verify that the clinical diagnosis was not later revised. Only 1 study $^{68}$ allowed us to evaluate imaging as the reference standard in addition to the clinical diagnosis and $\mathrm{TAB}$.

\section{Evaluation of Bias}

Patient selection was the principal source of bias (eFigures 2 and 3 in the Supplement). Studies using TAB as the reference standard may have been more prone to selection bias because a sufficient index of clinical suspicion is required to order this invasive test. Conversely, studies using the clinical diagnosis as the reference standard were at high risk of bias because the index test result contributed to the clinical diagnostic decision.

Diagnostic Value of Symptoms and Demographic Features In studies reporting the sex of patients ( $n=7798), 2605$ (33.4\%) of patients were male and $5193(66.6 \%)$ were female. Although headache is considered to be a key symptom for GCA, the positive and negative LRs for headache did not meet our prespecified threshold for statistical significance (Table 2). Double vision provided a positive LR of 1.72 (95\% CI, 1.122.63). Positive LRs of more than 2.00 were found for limb claudication (6.01; 95\% CI, 1.38-26.16), jaw claudication (4.90; 95\% CI, 3.74-6.41), and a previous diagnosis of polymyalgia rheumatica (2.07; 95\% CI, 0.92-4.65), whereas being older than 70 years had a negative LR of less than 0.50 (0.48; 95\% CI, 0.270.86). The forest plots and HSROC curves indicated substantial heterogeneity for all statistically significant index tests except for jaw claudication (eFigures 4 and 5 in the Supplement). Overall, we found little evidence of publication bias by evaluation of funnel plot asymmetry (eFigure 6 in the Supplement). Symptoms reported by less than 4 studies are shown in eTable 6 in the Supplement.

Diagnostic Value of Physical Signs and Laboratory Tests A positive LR of more than 2.00 occurred for findings related to temporal artery thickening (LR, 4.70; 95\% CI, 2.65-8.33), temporal artery loss of pulse (3.25; 95\% CI, 2.49-4.23), temporal tenderness (3.14; 95\% CI, 1.14-8.65), an abnormal temporal artery (2.29; 95\% CI, 1.61-3.26), anterior ischemic optic neuropathy (2.15; 95\% CI, 1.53-3.03), erythrocyte sedimentation rate (ESR) of greater than 60 (2.40; 95\% CI, 1.71-3.36), 80 (2.79; 95\% CI, 1.78-4.37), and $100 \mathrm{~mm} / \mathrm{h}$ (3.11; 95\% CI, 1.436.78), and a platelet count of greater than $400 \times 10^{3} / \mu \mathrm{L}$ all (to convert to $\times 10^{9} / \mathrm{L}$, multiply by 1 ) (3.75; 95\% CI, 2.12-6.64) (Table 3). Negative LRs of less than 0.50 occurred for an ESR of more than $40 \mathrm{~mm} / \mathrm{h}(0.18$; 95\% CI, 0.08-0.44), more than $50 \mathrm{~mm} / \mathrm{h}$ (0.48; 95\% CI, 0.38-0.62), and more than $60 \mathrm{~mm} / \mathrm{h}$ (0.42; 95\% CI, 0.28-0.61), CRP level of at least $2.5 \mathrm{mg} / \mathrm{dL}$ (0.38; 95\% CI, 0.25-0.59), or a CRP level of greater than the reference value (0.40; 95\% CI, 0.29-0.56). Overall, moderate heterogeneity and little funnel plot asymmetry was observed (eFig- ures 4, 5, and 6 in the Supplement). Physical findings reported by fewer than 4 studies are shown in eTable 7 in the Supplement.

\section{Sensitivity Analyses}

Results of our sensitivity analyses are provided in eTables 8 to 10 in the Supplement. We found comparable LRs in our comparison of studies with different reference standards (TAB vs clinical diagnosis) or study design (prospective vs retrospective). A pretreatment elevated CRP level showed a sensitivity of $90.1 \%$ (95\% CI, 76.3\%-96.3\%) and a negative LR of 0.38 (95\% CI, 0.17-0.81) for a diagnosis of GCA. A pretreatment ESR of greater than $50 \mathrm{~mm} / \mathrm{h}$ had a sensitivity of $87.5 \%$ (95\% CI, 78.3\%93.1\%) and negative LR of 0.27 (95\% CI, 0.13-0.57).

\section{Discussion}

\section{Main Findings}

This updated meta-analysis provides more precise estimates of LRs associated with symptoms, signs, and laboratory features of GCA. Features that, if present, should upgrade the level of suspicion for GCA are limb claudication; jaw claudication; various temporal artery abnormalities; a platelet count of greater than $400 \times 10^{3} / \mu \mathrm{L}$; ESRs of greater than 60,80 , and $100 \mathrm{~mm} / \mathrm{h}$; and anterior ischemic optic neuropathy. Features that should downgrade the level of suspicion for GCA are 70 years or younger; a CRP level in the reference range or less than $2.5 \mathrm{mg} / \mathrm{dL}$; and an ESR of no greater than 40,50 , or $60 \mathrm{~mm} / \mathrm{h}$. For most patients with suspected GCA, no single feature is likely to shift pretest probability sufficiently to render further investigation for GCA unnecessary. However, these likelihood ratios may inform clinical decisions, including selection and timing of investigations, and whether to immediately commence high-dose glucocorticoid therapy or await further test results. ${ }^{88,89}$

\section{Association With Other Studies}

Our findings confirm and extend those of the previous meta-analysis, ${ }^{11}$ which had included 21 studies of 2680 patients. We were able to show that an elevated ESR, especially greater than $60 \mathrm{~mm} / \mathrm{h}$, is informative in suggesting a diagnosis of GCA. We improved the precision and clinical utility of the summary estimates. For example, the previous meta-analysis ${ }^{11}$ estimated the positive LR for double vision as 3.4 (95\% CI, 1.3-8.6); with greater patient numbers, we estimate the positive LR as 1.72 (95\% CI, 1.12-2.63). We were also able to evaluate the diagnostic accuracy of further features, including transient loss of vision, cerebrovascular accident, limb claudication, central retinal artery occlusion, CRP levels, and platelet counts. Furthermore, we conducted sensitivity analyses to evaluate for bias arising from choice of reference standard, prospective vs retrospective studies, and whether all laboratory tests were explicitly stated as occurring before treatment.

Various tools have been developed that could help to estimate GCA probability. These tools require assessment of a limited set of clinical and laboratory features that were originally selected by expert opinion and then weighted based on 


\begin{tabular}{|c|c|c|c|c|c|c|c|}
\hline Finding by study & $\begin{array}{l}\text { No. of } \\
\text { patients (No. } \\
\text { of cohorts) }\end{array}$ & $\begin{array}{l}\text { Sensitivity } \\
(95 \% \mathrm{Cl}), \% \\
\end{array}$ & \multicolumn{2}{|c|}{$\begin{array}{l}\text { Specificity } \\
(95 \% \mathrm{Cl}), \%\end{array}$} & $\begin{array}{l}\text { Diagnostic OR } \\
(95 \% \mathrm{Cl})\end{array}$ & $\begin{array}{l}\text { Positive LR } \\
(95 \% \mathrm{Cl})\end{array}$ & $\begin{array}{l}\text { Negative LR } \\
(95 \% \mathrm{Cl})\end{array}$ \\
\hline \multicolumn{8}{|l|}{ Demographics } \\
\hline \multicolumn{8}{|l|}{ Age, y } \\
\hline$>60^{\mathrm{a}}$ & $261(7)$ & $96.6(76.0-99.6)$ & \multicolumn{2}{|c|}{$22.6(15.4-31.8)$} & $8.39(1.05-67.11)$ & $1.25(1.12-1.39)$ & $0.15(0.02-1.13)$ \\
\hline$>70^{\mathrm{a}}$ & $261(7)$ & $73.5(49.5-88.7)$ & \multicolumn{2}{|c|}{$55.3(39.2-70.3)$} & $3.42(1.68-6.96)$ & $1.64(1.29-2.09)$ & $0.48(0.27-0.86)^{x}$ \\
\hline$>80^{\mathrm{b}}$ & $208(6)$ & $19.0(10.4-32.0)$ & \multicolumn{2}{|c|}{$85.1(73.4-92.1)$} & $1.33(0.62-2.86)$ & $1.27(0.67-2.40)$ & $0.95(0,84-1.09)$ \\
\hline Male $^{c}$ & $7798(42)$ & $31.7(29.6-33.9)$ & \multicolumn{2}{|c|}{$64.9(62.5-67.2)$} & $0.86(0.77-0.96)$ & $0.90(0.84-0.97)$ & $1.05(1.01-1.09)$ \\
\hline \multicolumn{8}{|l|}{ Symptoms } \\
\hline \multicolumn{8}{|l|}{ Cranial } \\
\hline Headache $^{d}$ & $6918(36)$ & $72.2(68.3-75.8)$ & \multicolumn{2}{|c|}{$45.7(39.1-52.4)$} & $2.19(1.72-2.78)$ & $1.33(1.19-1.48)$ & $0.61(0.53-0.70)$ \\
\hline Temporal headache $^{e}$ & $545(4)$ & $65.9(37.4-86.2)$ & \multicolumn{2}{|c|}{$31.8(14.1-57.1)$} & $0.90(0.56-1.46)$ & $0.97(0.82-1.14)$ & $1.07(0.78-1.47)$ \\
\hline Scalp tenderness ${ }^{f}$ & $2951(15)$ & $38.9(31.7-46.7)$ & \multicolumn{2}{|c|}{$78.9(69.7-85.9)$} & $2.39(1.70-3.34)$ & $1.85(1.40-2.44)$ & $0.77(0.71-0.84)$ \\
\hline Jaw claudication ${ }^{9}$ & $6867(35)$ & $37.5(33.8-41.3)$ & \multicolumn{2}{|c|}{$92.3(89.6-94.4)$} & $7.24(5.45-9.62)$ & $4.90(3.74-6.41)^{x}$ & $0.68(0.64-0.71)$ \\
\hline Visual disturbance $^{\mathrm{h}}$ & $3023(25)$ & $33.9(29.6-38.4)$ & \multicolumn{2}{|c|}{$71.8(66.7-76.4)$} & $1.30(1.06-1.60)$ & $1.20(1.04-1.39)$ & $0.92(0.86-0.98)$ \\
\hline Loss of vision ${ }^{i}$ & $4585(14)$ & $21.7(15.1-30.3)$ & \multicolumn{2}{|c|}{$85.3(76.2-91.3)$} & $1.61(1.21-2.14)$ & $1.48(1.15-1.91)$ & $0.92(0.88-0.96)$ \\
\hline Transient loss of vision ${ }^{j}$ & $1181(9)$ & $10.7(7.1-16.0)$ & \multicolumn{2}{|c|}{$92.9(86.6-96.4)$} & $1.57(0.88-2.82)$ & $1.51(0.88-2.60)$ & $0.96(0.92-1.01)$ \\
\hline Double visionk & $3799(8)$ & $6.5(4.5-9.3)$ & \multicolumn{2}{|c|}{$96.2(93.2-97.9)$} & $1.76(1.13-2.75)$ & $1.72(1.12-2.63)$ & $0.97(0.95-0.99)$ \\
\hline Cerebrovascular accident ${ }^{\mathrm{l}}$ & $1089(5)$ & $2.6(1.3-5.1)$ & \multicolumn{2}{|c|}{$95.9(89.0-98.5)$} & $0.62(0.23-1.63)$ & $0.63(0.25-1.59)$ & $1.02(0.98-1.06)$ \\
\hline \multicolumn{8}{|l|}{ Systemic } \\
\hline $\begin{array}{l}\text { Constitutional } \\
\text { symptoms }\end{array}$ & $1274(8)$ & $62.5(35.5-83.5)$ & \multicolumn{2}{|c|}{$46.8(29.1-65.2)$} & $1.47(0.89-2.41)$ & $1.17(1.00-1.38)$ & $0.80(0.56-1.14)$ \\
\hline Malaise $^{n}$ & $1267(10)$ & $55.5(44.0-66.4)$ & \multicolumn{2}{|c|}{$51.7(38.8-64.4)$} & $1.33(1.02-1.75)$ & $1.15(1.00-1.33)$ & $0.86(0.75-0.99)$ \\
\hline Anorexia $^{\circ}$ & $1932(8)$ & $40.2(28.0-53.8)$ & \multicolumn{2}{|c|}{$74.5(64.5-82.5)$} & $1.97(1.51-2.57)$ & $1.58(1.33-1.88)$ & $0.80(0.71-0.91)$ \\
\hline Weight loss ${ }^{p}$ & $2882(18)$ & $39.3(31.0-48.3)$ & \multicolumn{2}{|c|}{$76.7(72.2-80.6)$} & $2.13(1.64-2.77)$ & $1.69(1.44-1.98)$ & $0.79(0.71-0.89)$ \\
\hline Fever $^{\mathrm{q}}$ & $3091(23)$ & $26.7(19.8-34.9)$ & $78.0(68.4$ & 5.3) & $1.29(1.03-1.62)$ & $1.21(1.01-1.46)$ & $0.94(0.90-0.99)$ \\
\hline Other & & & & & & & \\
\hline Myalgiar $^{r}$ & $1855(15)$ & $39.8(35.0-44.9)$ & $57.5(46.9$ & 7.4) & $0.90(0.61-1.31)$ & $0.94(0.75-1.17)$ & $1.05(0.89-1.23)$ \\
\hline $\mathrm{PMR}^{\mathrm{s}}$ & $2814(23)$ & $33.4(27.5-39.8)$ & $74.3(65.9$ & $1.2)$ & $1.45(1.14-1.84)$ & $1.30(1.08-1.56)$ & $0.90(0.84-0.95)$ \\
\hline Previous PMR ${ }^{t}$ & $519(4)$ & $19.1(13.4-26.5)$ & $90.8(82.3$ & 5.4) & $2.32(0.92-5.82)$ & $2.07(0.92-4.65)$ & $0.89(0.79-1.00)$ \\
\hline Arthralgia" & $656(6)$ & $25.4(15.5-38.6)$ & $73.3(64.6$ & $0.6)$ & $0.94(0.60-1.46)$ & $0.95(0.68-1.33)$ & $1.02(0.91-1.14)$ \\
\hline Limb claudication ${ }^{v, w}$ & $405(6)$ & $19.6(12.5-29.4)$ & $96.7(84.2$ & 9.4) & $7.23(1.62-32.21)$ & $6.01(1.38-26.16)^{x}$ & $0.83(0.76-0.91)$ \\
\hline Abbreviations: LR, likelihood & io; OR, odd & PMR, polymyalgi & & ${ }^{\mathrm{m}}$ Fron & 3 of the analyzed studi & es. ${ }^{16,33,37,46,51,61,64,69}$ & \\
\hline rheumatica. & & & & ${ }^{\mathrm{n}}$ Fron & 0 of the analyzed stuc & es. ${ }^{16,17,36,52,58,71,73,80,8}$ & \\
\hline a From 7 of the analyzed studie & s. ${ }^{28,30,44,50,53,71}$ & & & ${ }^{\circ}$ Fron & 3 of the analyzed studi & es. ${ }^{16,17,39,58,73,80,84,87}$ & \\
\hline${ }^{\mathrm{b}}$ From 6 of the analyzed studie & es. ${ }^{28,30,44,50,53,7}$ & & & PFron & 8 of the analyzed stuc & es. ${ }^{16,24,25,34,36,39,43,54}$ & $61,69,71,73,79,80,82,84,87$ \\
\hline $\begin{array}{l}\text { C From } 43 \text { of the analyzed stud } \\
69-71,73-77,80-82,84,87\end{array}$ & ies. $^{14,15,17,26,27,29}$ & 37,43-45,47,49-52,54,55, & $1.62,64,65$ & $\begin{array}{l}{ }^{\mathrm{a}} \text { Fron } \\
\text { stud }\end{array}$ & $\begin{array}{l}3 \text { of the analyzed } \\
5.16,32,35,36,39,41,43,47-4\end{array}$ & $, 52,54,55,57,58,61,65,69,71,7$ & $5,80,84$ \\
\hline $\begin{array}{l}{ }^{d} \text { From } 36 \text { of the analyzed stud } \\
71-7780.82-84.87\end{array}$ & ies. ${ }^{15,17,29,32,35-37}$ & $39,43,45-49,52,54,55,57$ & 1,64-66,69. & r Fron & 5 of the analyzed stud & es. ${ }^{16,35,36,43,47,52,55,57,5}$ & $51,69,73,75,80,84$ \\
\hline e From 4 of the analyzed studie & s. $16,27,33,34$ & & & $\begin{array}{l}\text { s Fron } \\
\text { stud }\end{array}$ & $\begin{array}{l}23 \text { of the analyzed } \\
5.17,24,25,32-34,37,39,41,4\end{array}$ & $48,49,53,58,60,64-66,71,7$ & 82,86 \\
\hline${ }^{f}$ From 15 of the analyzed stud & es. ${ }^{16,17,27,33,39,49}$ & $2,54,55,60,61,66,69,73,8$ & & ${ }^{\mathrm{t}}$ Fron & 4 of the analyzed studi & es. ${ }^{16,32,54,79}$ & \\
\hline $\begin{array}{l}{ }^{g} \text { From } 35 \text { of the analyzed stud } \\
75-77,80,82,84,87\end{array}$ & ies. ${ }^{15,17,27,32-37,3}$ & $, 45-48,52-55,57,58,61,6$ & 9.71-73, & ${ }^{\mathrm{u}}$ Fron & 5 of the analyzed studi & es. ${ }^{16,39,58,75,80,84}$ & \\
\hline & & & & ${ }^{v}$ Fron & 5 of the analyzed studi & es. ${ }^{29,35,51,69,71,82}$ & \\
\hline studies. ${ }^{24,25,27,29,32,34,35,39,41}$ & $46,47,54,58,61,63$ & $9.71,73,76,80,82,84$ & & $\begin{aligned}{ }^{w} \text { Limb } \\
\text { anot }\end{aligned}$ & $\begin{array}{l}\text { laudication was restric } \\
\text { er study. }{ }^{29}\end{array}$ & ed to the arms in on & dy $y^{71}$ and to the legs in \\
\hline ' From 14 of the analyzed stud & es. ${ }^{15,39,43,45,49}$ & 7.63,69,72,74,75, 77,87 & & $\times$ Stati & ically significant due tc & summary estimate of & positive LR of greater \\
\hline${ }^{j}$ From 9 of the analyzed studi & es. ${ }^{16,17,39,43,55,67,6}$ & $9,79,86$ & & than & .00 or the negative LR & of less than 0.50 and & $5 \% \mathrm{Cl}$ not including \\
\hline${ }^{\mathrm{k}}$ From 8 of the analyzed studi & es. $15,17,39,43,49,69$ & & & 1.00 & & & \\
\hline ' From 5 of the analyzed studie & s. ${ }^{43,46,61,63,73}$ & & & & & & \\
\hline
\end{tabular}

expert opinion or statistical methods. ${ }^{8,9}$ Interestingly, both tools contain features, such as sex, that were not very helpful in changing GCA probability according to our meta-analysis. Some clinical features in these tools, such as symptom dura- tion and alternative diagnosis, ${ }^{8}$ could not be included in our meta-analysis owing to lack of published data.

Our meta-analysis indicates that some features considered classic for GCA, such as headache, scalp tenderness, and 


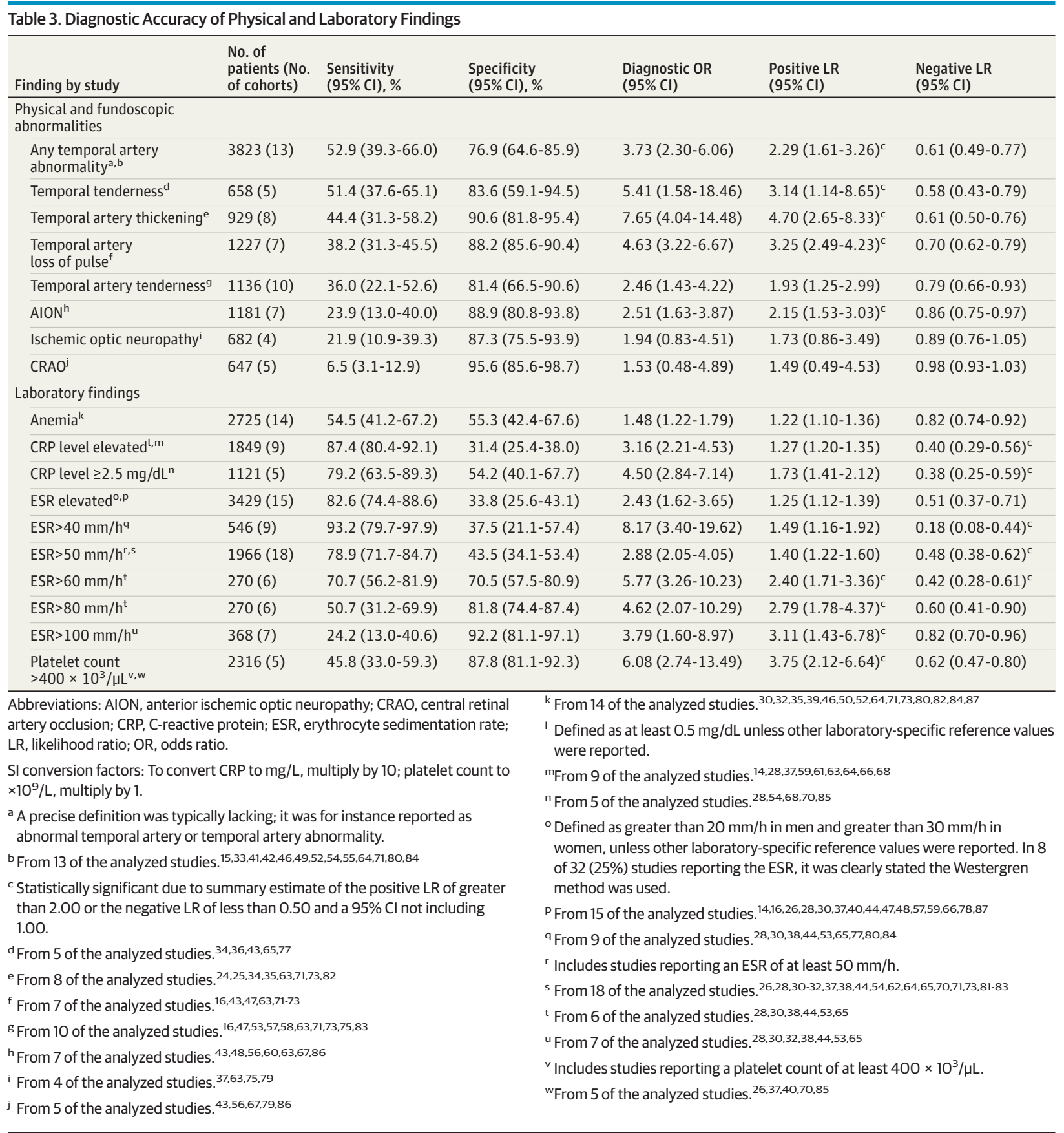

constitutional symptoms, have limited use for upgrading or downgrading the clinical probability of GCA. This does not mean, however, that these symptoms are irrelevant. Our metaanalysis shows that the prevalence of these classic features is high among patients with and without GCA, suggesting that the diagnostic value of these symptoms may have been used up earlier in the care pathway. ${ }^{90}$ Headache is important in prompting suspicion of GCA and onward referral to a specialist, but once that referral decision has been made, clinicians should be cautious about overvaluing the diagnostic significance of headache and should evaluate patients for the other features identified in our meta-analysis as informative for a final diagnosis of GCA.

\section{Limitations}

Our study was limited by the quality of the studies included. Although we performed a comprehensive search for published studies, we cannot exclude that relevant data was omitted owing to exclusion of non-English articles and conference abstracts. No unpublished data were obtained via contact with authors.

Several sources of bias were present in our metaanalysis. First, studies using TAB may have been at risk of selection bias because the decision for TAB necessarily depends on the presence of clinical and laboratory features to justify this invasive test. Second, clinical diagnosis is subjective and relies on clinical and laboratory features as well as fur- 
ther tests; this circularity could lead to overestimation of the diagnostic accuracy of index tests. Third, many studies were retrospective cohort studies, which could have introduced further selection bias. We mitigated these risks of bias by performing sensitivity analyses, which did not show substantial differences between studies with distinct reference standards or between studies with retrospectively and prospectively gathered data.

The reference standards for GCA may have additional limitations. Although the sensitivity of TAB may be $77 \%$ for fulfilment of the American College of Rheumatology 1990 criteria for GCA, ${ }^{91}$ it is likely lower for the clinical diagnosis in daily clinical practice. ${ }^{6}$ Some studies in our meta-analysis ${ }^{46,68,71,75-77,82}$ reported a subgroup of patients with TAB findings that were negative for GCA. Patients with GCA may have had TAB findings negative for GCA in other studies, but these patients were simply classified as not having GCA. Thus, the diagnostic accuracy of clinical and laboratory features might have been underestimated. The clinical diagnosis of GCA might be subjective and strongly related to the experience of the individual physician making the diagnosis. The clinical diagnosis was only ascertained by follow-up in a minority of studies. Nevertheless, we observed comparable LRs of clinical and laboratory features in studies using TAB or the clinical diagnosis as the reference standard.

A clear definition of symptoms was lacking in the studies included in our meta-analysis. This might be relevant for a symptom such as jaw claudication. Jaw claudication typically occurs after 2 to 3 minutes of chewing, ${ }^{92}$ but temporomandibular joint pain is common in older people and also causes pain with chewing. Lack of a clear definition of jaw claudication might possibly inflate the LR of this clinical feature, because it allows clinicians to classify aching on chewing as either jaw claudication or temporomandibular joint pain based on the clinical judgment that GCA is likely or not. Because jaw claudication is not described in any other disease and might be considered almost pathognomonic of GCA, clinicians may be reluctant to document jaw claudication unless they are fairly sure for other reasons that the patient has GCA.

Glucocorticoid treatment may be commenced immediately when GCA is suspected. This treatment could have affected index test results, particularly the laboratory tests. It was surprising that only few reports explicitly stated that the laboratory test results were obtained before treatment. Our sen- sitivity analysis for pretreatment laboratory measures could only be performed for an elevated CRP level and an ESR of greater than $50 \mathrm{~mm} / \mathrm{h}$. These pretreatment laboratory features tended to show better sensitivity and negative LRs than those obtained in the main study analysis.

The meta-analysis method we used required us to dichotomize continuous variables associated with GCA (age and laboratory values), which is inefficient and likely results in underestimation of diagnostic utility. However, individual patient data meta-analysis would have been needed to overcome this.

Study heterogeneity was observed for various clinical and laboratory features with relevant LRs. Additional prospective studies are needed to confirm the summary estimates of these features. We therefore recommend that complete sets of clinical and pretreatment laboratory data are reported in diagnostic cohort studies, either in summary tables or as raw data. This process would allow investigators to determine summary estimates of diagnostic accuracy parameters with more precision. Prospective studies would ideally consist of all patients who have been evaluated for GCA by every specialty or department in a hospital. ${ }^{90}$

\section{Conclusions}

This systematic review and meta-analysis highlight the clinical and laboratory features that may be informative in making a diagnosis of GCA and that should be assessed when evaluating patients with suspected GCA. They should also be reported in future diagnostic cohort studies. Clinicians should obtain a comprehensive history, physical examination, and laboratory evaluation for each patient suspected of having GCA. No single symptom, physical sign, or laboratory test is sufficient to completely rule in or rule out GCA. An additional imaging test or TAB is typically needed to make a confident diagnosis of GCA. Our study could not determine whether individual LRs can be combined, or whether there is collinearity between particular features (eg, ESRs and CRP levels with constitutional symptoms). Nonetheless, this study provides important data that could inform a future bayesian probability revision approach to investigation, diagnosis, and management of suspected GCA, which would need to be prospectively validated in future studies.

\section{ARTICLE INFORMATION}

Accepted for Publication: May 25, 2020.

Published Online: August 17, 2020. doi:10.1001/jamainternmed.2020.3050

Open Access: This is an open access article distributed under the terms of the CC-BY License. (c) 2020 van der Geest KSM et al. JAMA Internal Medicine.

Author Contributions: Drs Brouwer and Mackie contributed equally as co-last authors.

Dr van der Geest had full access to all the data in the study and takes responsibility for the integrity of the data and the accuracy of the data analysis. Concept and design: van der Geest, Brouwer, Mackie.
Acquisition, analysis, or interpretation of data: All authors. Drafting of the manuscript: van der Geest, Brouwer, Mackie.

Critical revision of the manuscript for important intellectual content: All authors.

Statistical analysis: van der Geest, Brouwer. Administrative, technical, or material support: van der Geest, Brouwer. Supervision: Brouwer.

Conflict of Interest Disclosures: Dr van der Geest reported receiving a speaker fee from Roche paid to the University Medical Center Groningen. Dr Brouwer reported receiving consultancy and speaker fees from Roche paid to the University
Medical Center Groningen. Dr Mackie reported receiving support from Roche for attendance of the 2019 European League Against Rheumatism meeting as a coapplicant on a research grant receiving consultancy fees from Roche and Sanofi SA on behalf of Leeds Institute of Rheumatic and Musculoskeletal Medicine; and serving as a trial investigator for GlaxoSmithKline and Sanofi SA. No other disclosures were reported.

Funding/Support: This study was supported by TARGET partnership grant MR/NO11775/1 from the Medical Research Council (Dr Mackie) and the Mandema Stipend from the University Medical Center Groningen (Dr van der Geest). 
Role of the Funder/Sponsor: The sponsors had no role in the design and conduct of the study; collection, management, analysis, and interpretation of the data; preparation, review, or approval of the manuscript; and decision to submit the manuscript for publication.

Additional Contributions: We thank Karin Sijtsma, medical science librarian at the Central Medical Library of the University Medical Center Groningen, for her advice on the search strategy. She received no compensation for this work.

\section{REFERENCES}

1. Diamantopoulos AP, Haugeberg G, Lindland A Myklebust $\mathrm{G}$. The fast-track ultrasound clinic for early diagnosis of giant cell arteritis significantly reduces permanent visual impairment: towards a more effective strategy to improve clinical outcome in giant cell arteritis? Rheumatology (Oxford). 2016; 55(1):66-70. doi:10.1093/rheumatology/kev289

2. Prior JA, Ranjbar H, Belcher J, et al. Diagnostic delay for giant cell arteritis - a systematic review and meta-analysis. BMC Med. 2017;15(1):120. doi:10.1186/s12916-017-0871-z

3. Mackie SL, Dejaco C, Appenzeller S, et al. British Society for Rheumatology guideline on diagnosis and treatment of giant cell arteritis. Rheumatology (Oxford). 2020;59(3):e1-e23. doi:10.1093/ rheumatology/kez672

4. Hunder GG, Bloch DA, Michel BA, et al. The American College of Rheumatology 1990 criteria for the classification of giant cell arteritis. Arthritis Rheum. 1990;33(8):1122-1128. doi:10.1002/art. 1780330810

5. Seeliger B, Sznajd J, Robson JC, et al. Are the 1990 American College of Rheumatology vasculitis classification criteria still valid? Rheumatology (Oxford). 2017;56(7):1154-1161. doi:10.1093/ rheumatology/kex075

6. Banz Y, Stone JH. Why do temporal arteries go wrong? principles and pearls from a clinician and a pathologist. Rheumatology (Oxford). 2018;57(suppl 2):ii3-ii10. doi:10.1093/rheumatology/kex524

7. Dejaco C, Ramiro S, Duftner C, et al. EULAR recommendations for the use of imaging in large vessel vasculitis in clinical practice. Ann Rheum Dis. 2018;77(5):636-643. doi:10.1136/annrheumdis-2017 212649

8. Laskou F, Coath F, Mackie SL, Banerjee S, Aung T Dasgupta B. A probability score to aid the diagnosis of suspected giant cell arteritis. Clin Exp Rheumatol. 2019;37(2)(suppl 117):104-108.

9. Ing EB, Lahaie Luna $G$, Toren $A$, et al. Multivariable prediction model for suspected giant cell arteritis: development and validation. Clin Ophthalmol. 2017;11:2031-2042. doi:10.2147/OPTH. S151385

10. Wilson MC, Henderson MC, Smetana GW Chapter 5: Evidence-based clinical decision making In: Wilson MC, Henderson MC, Smetana GW, eds. The Patient History: An Evidence-Based Approach to Differential Diagnosis. 2nd ed. McGraw-Hill; 2012.

11. Smetana GW, Shmerling RH. Does this patient have temporal arteritis? JAMA. 2002;287(1):92-101. doi:10.1001/jama.287.1.92

12. Lijmer JG, Mol BW, Heisterkamp S, et al Empirical evidence of design-related bias in studies of diagnostic tests. JAMA. 1999;282(11):1061-1066. doi:10.1001/jama.282.11.1061
13. Rutjes AW, Reitsma JB, Di Nisio M, Smidt N, van Rijn JC, Bossuyt PM. Evidence of bias and variation in diagnostic accuracy studies. CMAJ. 2006;174(4) 469-476. doi:10.1503/cmaj.050090

\section{De Lott LB, Burke JF; Michigan}

Neuro-Ophthalmology Research Consortium. Use of laboratory markers in deciding whether to perform temporal artery biopsy. JAMA Ophthalmol 2015;133(5):605-606. doi:10.1001/jamaophthalmol. 2014.5861

15. Ing EB, Miller NR, Nguyen A, et al. Neural network and logistic regression diagnostic prediction models for giant cell arteritis: development and validation. Clin Ophthalmol. 2019;13:421-430. doi:10.2147/OPTH.S193460

16. Toren A, Weis E, Patel V, Monteith B, Gilberg S, Jordan D. Clinical predictors of positive temporal artery biopsy. Can J Ophthalmol. 2016;51(6):476-481. doi:10.1016/j.jcjo.2016.05.021

17. van der Geest KSM, Borg F, Kayani A, et al. Novel ultrasonographic Halo score for giant cell arteritis: assessment of diagnostic accuracy and association with ocular ischaemia. Ann Rheum Dis. 2020;79(3):393-399. doi:10.1136/annrheumdis-2019216343

18. Liberati A, Altman DG, Tetzlaff J, et al. The PRISMA statement for reporting systematic reviews and meta-analyses of studies that evaluate healthcare interventions: explanation and elaboration. BMJ. 2009;339:b2700. doi:10.1136/ bmj.b2700

19. Dejaco C, Duftner C, Buttgereit F, Matteson EL, Dasgupta B. The spectrum of giant cell arteritis and polymyalgia rheumatica: revisiting the concept of the disease. Rheumatology (Oxford). 2017;56(4): 506-515.

20. Whiting PF, Rutjes AW, Westwood ME, et al; QUADAS-2 Group. QUADAS-2: a revised tool for the quality assessment of diagnostic accuracy studies. Ann Intern Med. 2011;155(8):529-536. doi:10.7326/ 0003-4819-155-8-201110180-00009

21. Macaskill P, Gatsonis C, Deeks JJ, Harbord RM, Takwoingi Y. Chapter 10: Analysing and presenting results. In: Deeks JJ, Bossuyt PM, Gatsonis C, eds. Cochrane Handbook for Systematic Reviews of Diagnostic Test Accuracy, Version 1.0. The Cochrane Collaboration; 2010. Accessed April 5, 2019. http:// srdta.cochrane.org/

22. McGee S. Simplifying likelihood ratios. J Gen Intern Med. 2002;17(8):646-649. doi:10.1046/ j.1525-1497.2002.10750.x

23. Deeks JJ, Macaskill P, Irwig L. The performance of tests of publication bias and other sample size effects in systematic reviews of diagnostic test accuracy was assessed. J Clin Epidemiol. 2005;58 (9):882-893. doi:10.1016/j.jclinepi.2005.01.016

24. Aschwanden M, Daikeler $T$, Kesten $F$, et al. Temporal artery compression sign: a novel ultrasound finding for the diagnosis of giant cell arteritis. Ultraschall Med. 2013;34(1):47-50.

25. Aschwanden M, Imfeld S, Staub D, et al. The ultrasound compression sign to diagnose temporal giant cell arteritis shows an excellent interobserver agreement. Clin Exp Rheumatol. 2015;33(2)(suppl 89):S-113-S-115.

26. Bilyk JR, Murchison AP, Leiby BT, et al. The utility of color duplex ultrasonography in the diagnosis of giant cell arteritis: a prospective, masked study [an American Ophthalmological
Society thesis]. Trans Am Ophthalmol Soc. 2018;115:T9.

27. Black R, Roach D, Rischmueller M, Lester SL, Hill CL. The use of temporal artery ultrasound in the diagnosis of giant cell arteritis in routine practice. Int J Rheum Dis. 2013:16(3):352-357. doi:10.1111/ 1756-185X.12108

28. Bley TA, Weiben O, Uhl M, et al. Assessment of the cranial involvement pattern of giant cell arteritis with $3 \mathrm{~T}$ magnetic resonance imaging. Arthritis Rheum 2005;52(8):2470-2477. doi:10.1002/art.21226

29. Bley TA, Reinhard M, Hauenstein C, et al. Comparison of duplex sonography and high-resolution magnetic resonance imaging in the diagnosis of giant cell (temporal) arteritis. Arthritis Rheum. 2008;58(8):2574-2578. doi:10.1002/art. 23699

30. Brittain GP, Mcllwaine GG, Bell JA, Gibson JM. Plasma viscosity or erythrocyte sedimentation rate in the diagnosis of giant cell arteritis? $\mathrm{Br} J$ Ophthalmol. 1991;75(11):656-659. doi:10.1136/bjo.75.11.656

31. Chan FLY, Lester $S$, Whittle SL, Hill CL. The utility of ESR, CRP and platelets in the diagnosis of GCA. BMC Rheumatol. 2019;3:14. doi:10.1186/ s41927-019-0061-z

32. Chmelewski WL, McKnight KM, Agudelo CA Wise CM. Presenting features and outcomes in patients undergoing temporal artery biopsy: a review of 98 patients. Arch Intern Med. 1992;152 (8):1690-1695. doi:10.1001/archinte.1992. 00400200120022

33. Conway R, O'Neill L, McCarthy GM, et al. Performance characteristics and predictors of temporal artery ultrasound for the diagnosis of giant cell arteritis in routine clinical practice in a prospective cohort. Clin Exp Rheumatol. 2019;37(2) (suppl 117):72-78.

34. Croft AP, Thompson N, Duddy MJ, et al. Crania ultrasound for the diagnosis of giant cell arteritis: a retrospective cohort study. J R Coll Physicians Edinb. 2015;45(4):268-272. doi:10.4997/JRCPE.2015.403

35. Czihal M, Schröttle A, Baustel K, et al. B-mode sonography wall thickness assessment of the temporal and axillary arteries for the diagnosis of giant cell arteritis: a cohort study. Clin Exp Rheumatol. 2017;35(1)(suppl 103):128-133.

36. Diamantopoulos AP, Haugeberg G, Hetland H, Soldal DM, Bie R, Myklebust G. Diagnostic value of color Doppler ultrasonography of temporal arteries and large vessels in giant cell arteritis: a consecutive case series. Arthritis Care Res (Hoboken). 2014;66 (1):113-119. doi:10.1002/acr.22178

37. El-Dairi MA, Chang L, Proia AD, Cummings TJ, Stinnett SS, Bhatti MT. Diagnostic algorithm for patients with suspected giant cell arteritis. J Neuroophthalmol. 2015;35(3):246-253. doi:10.1097| WN0.0000000000000234

38. Eshaghian J, Goeken JA. C-reactive protein in giant cell (cranial, temporal) arteritis. Ophthalmology. 1980;87(11):1160-1166. doi:10.1016/S0161-6420(80) 35110-5

39. Fernandez-Herlihy L. Temporal arteritis: clinical aids to diagnosis. J Rheumatol. 1988;15(12):1797-1801.

40. Foroozan R, Danesh-Meyer H, Savino PJ, Gamble G, Mekari-Sabbagh ON, Sergott RC. Thrombocytosis in patients with biopsy-proven giant cell arteritis. Ophthalmology. 2002;109(7): 1267-1271. doi:10.1016/S0161-642O(02)01076-X 
41. Gabriel SE, O'Fallon WM, Achkar AA, Lie JT, Hunder GG. The use of clinical characteristics to predict the results of temporal artery biopsy among patients with suspected giant cell arteritis. J Rheumatol. 1995;22(1):93-96.

42. Ghinoi A, Zuccoli G, Nicolini A, et al. 1T magnetic resonance imaging in the diagnosis of giant cell arteritis: comparison with ultrasonography and physical examination of temporal arteries. Clin Exp Rheumatol. 2008;26(3) (suppl 49):S76-S80.

43. González-López JJ, González-Moraleja J, Burdaspal-Moratilla A, Rebolleda G, Núñez-Gómez-Álvarez MT, Muñoz-Negrete FJ. Factors associated to temporal artery biopsy result in suspects of giant cell arteritis: a retrospective, multicenter, case-control study. Acta Ophthalmol. 2013;91(8):763-768. doi:10.1111/j.1755-3768.2012. 02505.x

44. Gospe SM III, Amrhein TJ, Malinzak MD, Bhatti MT, Mettu P, El-Dairi MA. Magnetic resonance imaging abnormalities of the optic nerve sheath and intracranial internal carotid artery in giant cell arteritis. J Neuroophthalmol. Published online October 8, 2019. doi:10.1097/WNO. 0000000000000860

45. Grosser SJ, Reddy RK, Tomsak RL, Katzin WE. Temporal arteritis in African Americans. Neuro-Ophthalmology. 1999;21(1):25-31. doi:10.1076/noph.21.1.25.3927

46. Grossman C, Barshack I, Koren-Morag N Ben-Zvi I, Bornstein G. Baseline clinical predictors of an ultimate giant cell arteritis diagnosis in patients referred to temporal artery biopsy. Clin Rheumatol. 2016;35(7):1817-1822. doi:10.1007/s10067-0163221-1

47. Habib HM, Essa AA, Hassan AA. Color duplex ultrasonography of temporal arteries: role in diagnosis and follow-up of suspected cases of temporal arteritis. Clin Rheumatol. 2012;31(2):231 237. doi:10.1007/s10067-011-1808-0

48. Hall JK, Volpe NJ, Galetta SL, Liu GT, Syed NA, Balcer LJ. The role of unilateral temporal artery biopsy. Ophthalmology. 2003;110(3):543-548. doi:10.1016/S0161-6420(02)01758-X

49. Hall S, Persellin S, Lie JT, O'Brien PC, Kurland LT, Hunder GG. The therapeutic impact of temporal artery biopsy. Lancet. 1983;2(8361):1217-1220. doi:10.1016/S0140-6736(83)91269-2

50. Hautzel H, Sander O, Heinzel A, Schneider M, Müller HW. Assessment of large-vessel involvement in giant cell arteritis with $18 \mathrm{~F}-\mathrm{FDG}$ PET: introducing an ROC-analysis-based cutoff ratio. J Nucl Med. 2008;49(7):1107-1113. doi:10.2967/jnumed.108. 051920

51. Hay B, Mariano-Goulart D, Bourdon A, et al. Diagnostic performance of ${ }^{18} \mathrm{~F}$-FDG PET-CT for large vessel involvement assessment in patients with suspected giant cell arteritis and negative temporal artery biopsy. Ann Nucl Med. 2019;33(7):512-520. doi:10.1007/s12149-019-01358-5

52. Hayreh SS, Podhajsky PA, Raman R, Zimmerman B. Giant cell arteritis: validity and reliability of various diagnostic criteria. Am J Ophthalmol. 1997;123(3):285-296. doi:10.1016/ S0002-9394(14)70123-0

53. Hedges TR III, Gieger GL, Albert DM. The clinical value of negative temporal artery biopsy specimens. Arch Ophthalmol. 1983;101(8):1251-1254. doi:10.1001/archopht.1983.01040020253019

54. Hop H, Mulder DJ, Sandovici M, et al. Diagnostic value of axillary artery ultrasound in patients with suspected giant cell arteritis. Rheumatology (Oxford). Published online April 2, 2020. https://doi-org.proxy-ub.rug.nl/10.1093/ rheumatology/keaa102

55. Imfeld S, Aschwanden M, Rottenburger $C$, et al. [18F]FDG positron emission tomography and ultrasound in the diagnosis of giant cell arteritis: congruent or complementary imaging methods? Rheumatology (Oxford). 2020;59(4):772-778. doi:10.1093/rheumatology/kez362

56. Ing E, Pagnoux $C$, Tyndel F, et al. Lower ocular pulse amplitude with dynamic contour tonometry is associated with biopsy-proven giant cell arteritis. Can J Ophthalmol. 2018;53(3):215-221. doi:10.1016/ j.jcjo.2017.10.027

57. Karahaliou M, Vaiopoulos G, Papaspyrou S, Kanakis MA, Revenas K, Sfikakis PP. Colour duplex sonography of temporal arteries before decision for biopsy: a prospective study in 55 patients with suspected giant cell arteritis. Arthritis Res Ther. 2006;8(4):R116. doi:10.1186/ar2003

58. Kent RB III, Thomas L. Temporal artery biopsy. Am Surg. 1990;56(1):16-21.

59. Kermani TA, Schmidt J, Crowson CS, et al. Utility of erythrocyte sedimentation rate and C-reactive protein for the diagnosis of giant cell arteritis. Semin Arthritis Rheum. 2012;41(6):866-871. doi:10.1016/j.semarthrit.2011.10.005

60. Knecht PB, Bachmann LM, Thiel MA, Landau K, Kaufmann C. Ocular pulse amplitude as a diagnostic adjunct in giant cell arteritis. Eye (Lond). 2015;29 (7):860-865. doi:10.1038/eye.2015.85

61. Lariviere D, Benali K, Coustet B, et al. Positron emission tomography and computed tomography angiography for the diagnosis of giant cell arteritis: a real-life prospective study. Medicine (Baltimore). 2016;95(30):e4146. doi:10.1097/MD. 0000000000004146

62. Lugo JZ, Deitch JS, Yu A, et al. Demographic and laboratory data may predict positive temporal artery biopsy. J Surg Res. 2011;170(2):332-335. doi:10.1016/j.jss.2011.03.013

63. Luqmani R, Lee $E$, Singh $S$, et al. The role of ultrasound compared to biopsy of temporal arteries in the diagnosis and treatment of giant cell arteritis (TABUL): a diagnostic accuracy and cost-effectiveness study. Health Technol Assess. 2016;20(90):1-238. doi:10.3310/hta20900

64. Marí $B$, Monteagudo $M$, Bustamante $E$, et al. Analysis of temporal artery biopsies in an 18-year period at a community hospital. Eur J Intern Med. 2009;20(5):533-536. doi:10.1016/j.ejim.2009.05. 002

65. Mohamed MS, Bates T. Predictive clinical and laboratory factors in the diagnosis of temporal arteritis. Ann R Coll Surg Engl. 2002;84(1):7-9.

66. Monti S, Floris A, Ponte CB, et al. The proposed role of ultrasound in the management of giant cell arteritis in routine clinical practice. Rheumatology (Oxford). 2018;57(1):112-119. doi:10.1093/ rheumatology/kex341

67. Moutray TN, Williams MA, Best JL. Suspected giant cell arteritis: a study of referrals for temporal artery biopsy. Can J Ophthalmol. 2008;43(4):445448. doi:10.3129/i08-070
68. Mukhtyar C, Myers H, Scott DGI, Misra A, Jones C. Validating a diagnostic GCA ultrasonography service against temporal artery biopsy and long-term clinical outcomes. Clin Rheumatol. 2020; 39(4):1325-1329. doi:10.1007/s10067-019-04772-2

69. Nielsen BD, Hansen IT, Keller KK, Therkildsen $P$, Gormsen LC, Hauge EM. Diagnostic accuracy of ultrasound for detecting large-vessel giant cell arteritis using FDG PET/CT as the reference. Rheumatology (Oxford). Published online December 6, 2019. https://doi-org.proxy-ub.rug.nl/ 10.1093/rheumatology/kez568

70. Oh LJ, Wong E, Andrici J, McCluskey P, Smith JEH, Gill AJ. Full blood count as an ancillary test to support the diagnosis of giant cell arteritis. Intern Med J. 2018;48(4):408-413. doi:10.1111/imj.13713

71. Oiwa H, Ichimura $\mathrm{K}$, Hosokawa $Y$, et al. Diagnostic performance of a temporal artery biopsy for the diagnosis of giant cell arteritis in Japan: a single-center retrospective cohort study. Intern Med. 2019;58(17):2451-2458. doi:10.2169/ internalmedicine.2788-19

72. Quinn EM, Kearney DE, Kelly J, Keohane C, Redmond HP. Temporal artery biopsy is not required in all cases of suspected giant cell arteritis. Ann Vasc Surg. 2012;26(5):649-654. doi:10.1016/ j.avsg.2011.10.009

73. Rodríguez-Pla A, Rosselló-Urgell J, Bosch-Gil JA, Huguet-Redecilla P, Vilardell-Tarres M. Proposal to decrease the number of negative temporal artery biopsies. Scand J Rheumatol. 2007;36(2):111-118. doi:10.1080/03009740600991646

74. Roncato C, Allix-Béguec C, Brottier-Mancini E, Gombert B, Denis G. Diagnostic performance of colour duplex ultrasonography along with temporal artery biopsy in suspicion of giant cell arteritis. Clin Exp Rheumatol. 2017;35(1)(suppl 103):119-122.

75. Roth AM, Milsow L, Keltner JL. The ultimate diagnoses of patients undergoing temporal artery biopsies. Arch Ophthalmol. 1984;102(6):901-903. doi:10.1001/archopht.1984.01040030721028

76. Sammel AM, Smith S, Nguyen K, et al. Assessment for varicella zoster virus in patients newly suspected of having giant cell arteritis. Rheumatology (Oxford). Published online November 27, 2019. doi:10.1093/rheumatology/kez556

77. Skaug TR, Midelfart A, Jacobsen G. Clinical usefulness of biopsy in giant cell arteritis. Acta Ophthalmol Scand. 1995;73(6):567-570. doi:10.1111/ j.1600-0420.1995.tb00340.x

78. Sommer F, Spörl E, Herber R, Pillunat LE, Terai $N$. Predictive value of positive temporal artery biopsies in patients with clinically suspected giant cell arteritis considering temporal artery ultrasound findings. Graefes Arch Clin Exp Ophthalmol. 2019; 257(10):2279-2284. doi:10.1007/s00417-01904430-y

79. Stacy RC, Gilbert AL, Rizzo JF III. Correlation of clinical profile and specific histopathological features of temporal artery biopsies. J Neuroophthalmol. 2015;35(2):127-133. doi:10.1097/ WN0.0000000000000213

80. Stuart RA. Temporary artery biopsy in suspected temporal arteritis: a five year survey. N Z Med J. 1989;102(874):431-433.

81. Suelves AM, España-Gregori E, Aviñó J, Rohrweck S, Díaz-Llopis M. Analysis of factors that determine the diagnostic yield of temporal artery 
biopsy. Arch Soc Esp Oftalmol. 2013;88(4):127-129. doi:10.1016/j.oftal.2012.06.027

82. Sundholm JKM, Pettersson T, Paetau A, Albäck A, Sarkola T. Diagnostic performance and utility of very high-resolution ultrasonography in diagnosing giant cell arteritis of the temporal artery. Rheumatol Adv Pract. 2019;3(2):rkzO18. doi:10.1093/rap/rkzO18

83. Varma D, O'Neill D. Quantification of the role of temporal artery biopsy in diagnosing clinically suspected giant cell arteritis. Eye (Lond). 2004;18 (4):384-388. doi:10.1038/sj.eye.6700677

84. Vilaseca J, González A, Cid MC, Lopez-Vivancos J, Ortega A. Clinical usefulness of temporal artery biopsy. Ann Rheum Dis. 1987;46(4):282-285. doi:10.1136/ard.46.4.282

85. Walvick MD, Walvick MP. Giant cell arteritis: laboratory predictors of a positive temporal artery biopsy. Ophthalmology. 2011;118(6):1201-1204. doi:10.1016/j.ophtha.2010.10.002

86. Wells KK, Folberg R, Goeken JA, Kemp JD Temporal artery biopsies: correlation of light microscopy and immunofluorescence microscopy. Ophthalmology. 1989;96(7):1058-1064. doi:10.1016/ S0161-642O(89)32791-6

87. Younge BR, Cook BE Jr, Bartley GB, Hodge DO, Hunder GG. Initiation of glucocorticoid therapy: before or after temporal artery biopsy? Mayo Clin Proc. 2004;79(4):483-491. doi:10.4065/79.4.483

88. Mackie SL, Brouwer E. What can negative temporal artery biopsies tell us? Rheumatology (Oxford). 2020;59(5):925-927. doi:10.1093/ rheumatology/kez628

89. Duftner C, Dejaco C, Sepriano A, Falzon L, Schmidt WA, Ramiro S. Imaging in diagnosis, outcome prediction and monitoring of large vesse vasculitis: a systematic literature review and meta-analysis informing the EULAR recommendations. RMD Open. 2018;4(1):e000612. doi:10.1136/rmdopen-2017-000612

90. Sackett DL, Haynes RB. The architecture of diagnostic research. BMJ. 2002;324(7336):539-541. doi:10.1136/bmj.324.7336.539

91. Rubenstein E, Maldini C, Gonzalez-Chiappe S, Chevret S, Mahr A. Sensitivity of temporal artery biopsy in the diagnosis of giant cell arteritis: a systematic literature review and meta-analysis. Rheumatology (Oxford). 2020;59(5):1011-1020. doi:10.1093/rheumatology/kez385

92. Kuo $\mathrm{CH}$, McCluskey P, Fraser CL. Chewing gum test for jaw claudication in giant-cell arteritis. N Engl J Med. 2016;374(18):1794-1795. doi:10.1056/ NEJMc1511420 